\title{
Digital Natives - The Journey Begins: Digital Technologies Action Research
}

\author{
Gayle Stone \\ Rangeville State School, Toowoomba, Australia
}

\section{Email address:}

gston1@eq.edu.au

\section{To cite this article:}

Gayle Stone. Digital Natives - The Journey Begins: Digital Technologies Action Research. Science Journal of Education. Vol. 8, No. 1, 2020, pp. 1-7. doi: 10.11648/j.sjedu.20200801.11

Received: April 13, 2019; Accepted: January 17, 2020; Published: February 11, 2020

\begin{abstract}
As educators our primary focus is to scaffold knowledge and concepts so that students are prepared for the future and ultimately the workforce. Due to the rapidly changing digital technological advances there has been debate in education on how we provide the skills and knowledge for students so that they become productive and valued members of society. When our current students are entering the work force many of the jobs that may be available have not yet been developed and this is why the platform of the curriculum area of Digital technology plays such a profound role in preparing our students for the future. The focus of the curriculum is to develop processes that enable students to enhance their problem solving skills and to work collaboratively. This skill based approach is in contrast to a purely knowledge based curriculum. At Rangeville State School I have developed a programme that lays the foundation for prep students to start developing those skills that are emphasised in the curriculum. The intent is then to build on those skills and process and to provide a whole school based programme that will help to enhance opportunities for our older students.
\end{abstract}

Keywords: Young Children, Digital Technologies, Sequential Thinking, Coding, Language Development

\section{Background}

Digital Technologies empowers students to move from being consumers of technologies to creators of technologies through the development of discreet skills that are specific to the subject area.

An example of this is how the use of ICT and Technologies has impacted on libraries and the role of librarians and how the future is uncertain in this field. [12] This has implications for our students. Now more than ever our students require digital skills and given that we don't know what the world will look like tomorrow, let alone in five or even ten years' time, we need to skill them for the unknown,

Statistically speaking:

a) More than $90 \%$ of Australia's current workforce will need digital skills to perform their roles in the next 2-5 years.

b) At least $50 \%$ will need advanced skills to configure and build digital systems.

c) $60 \%$ of Australian students are studying or training for jobs that will largely be automated in the near future.[8]
In 2016 Rangeville State School became a Digital Technologies Launch School for the Darling Downs region in Queensland. Over the last five years the school allocated a specialist teacher to teach ICT capabilities for Prep to Year five students. The Digital Technologies curriculum was implemented in 2016 for Prep to Year three students to develop student's digital literacy skills and to help prepare them for a digital future. Chawla discussed the importance of developing digital intelligence quotient (DQ) in children to enhance the skills they need to thrive in the digital economy. [5]

Whittaker surmises that problem-solving and reasoning can be developed in young children and is instrumental in developing higher order thinking skills.[15] To develop and nurture these qualities in our students I developed a study on implementing a series of planned activities designed to develop sequential thinking in students in Prep (5/6 yearolds). The premise for the research was to discover the impact of using supplementary unplugged activities in the classroom on Prep students' sequential thinking capacity. [16-37] Baseline data was taken at the end of term two (before the Prep unit commenced) and then tested again in 
week five of term four - after exposure for ten weeks in term three.

Throughout Term Three prep classes received an hour of Digital Technology lessons with the specialist and they were involved in activities that introduced and supported sequential thinking and coding. Activities were developed using Epstein's strategies to promote children's planning and thinking.

Research has identified the importance of using both ICT skills and developing problem solving skills in education and for future employment opportunities. [1, 10] Analysis of the harvested data was then undertaken to structure professional development in Digital Technologies to ensure that the skills of the teaching staff were upgraded to allow a consistent language and knowledge base to develop a scaffolded program across the school. This facilitated further Digital Technologies curriculum development.

\section{Project Aims}

Rangeville State School's aim is to create units of work where children have hands on experience with digital devices and to create digital savvy users, thus enabling lifelong learning. The emphasis at Rangeville is to develop both digital technologies and ICT application capabilities that exposes students to programming and using software to create digital solutions. This aligns to the Australian Curriculum that states the overarching idea of the Technologies' curriculum is creating preferred futures. Its aim is to 'provide students with opportunities to consider how solutions that are created now will be used in the future. Students will identify the possible benefits and risks of creating solutions. '[2]

The purpose of this project is to look at the benefits of implementing unplugged activities by the class teacher, to aid the development of Prep digital technology skills. [16-37] This would then structure the professional development of teachers in the curriculum area of Digital Technologies.

\section{Delivery of Curriculum}

At Rangeville there are two computer labs attached to the library with 30 desktop computers in each lab. One lab is used for specific Digital Technology lessons and the other lab is for class teachers to use for assessment (both summative and formative) and computer-generated activities. Students have been exposed to ICT capabilities since 2011 and in 2016 Rangeville introduced the Digital Technologies curriculum for Prep to year 3 students with the focus on developing a strong program for prep students.

A specialist teaches Prep to Year 4 students for one hour a week over a semester. Students in year three and four have access to the specialist and computer labs in Semester One and Prep to year 2 students have the same access in Semester 2. This allows the prep students to have six months at school before introducing them to the Digital Technology curriculum. The intention is to build on the skills and capabilities of the students in prep and to scaffold units of work for year one. Each subsequent year those students will be exposed to more complex Digital Skills with the aim of developing a set of transversal competencies that are independent of a learning area and develop skills so that students can be effective users of ICT in their everyday life. [6]

McQuiggan, Kosturko, McQuiggan and Sabourin explored the concept of using 'Mobile Learning' in the school system. [11] They proposed that the use of technologies can engage students in new ways and make educational experience more meaning by using a plethora of features that these devices offer. On this basis I developed a program that would allow students to use both mobile technology as well as having access to activities that used robots and computers. Prep students were given a one-hour lesson that is broken into two half hour lessons. This allows for a delineation of emphasis on each half. In the first half hour the focus is on exposing students to Digital Technologies such as digital cameras, software applications (including apps) and peripheral devices and developing lateral and creative thinking. The second half hour is on sequential thinking, coding and the use of the Beebots supplemented by the use of coding apps.

During Term three prep students had weekly lessons containing structured coding activities to develop both their sequential thinking and exposure to digital technology. In Term Four the focus is on teaching students to log on independently with supplementary activities involving programming Beebots using both the robots and software.

The purpose of the research is to ascertain the benefits of unplugged activities for prep students whilst developing their computational thinking. [16-37] The definition of computational thinking used for the project is from the Barefoot Computing Organisation and has been refined over the ensuing years by Bell \& Vahrenhold. [3, 4] The concept of using unplugged activities is inspired from Computer Unplugged. [16-37]

\section{The Project}

Four prep classes took part with classes having between 16 to 18 children in each. Two classes had access to only the weekly specialist lesson while the other two classes had a folder of supplementary unplugged activities given to their teacher. [16-37] These unplugged activities were run by the teacher in the classroom and while they used different learning areas, they all reinforced the concept of sequential thinking. [16-37] Activities were taken from a variety of sources and covered different key learning areas of the Australian Curriculum. Access to further ideas were given to the teachers via the 'Learning Place'. [6] The classes are all a similar size and have a balanced spectrum of abilities prevalent in each class.

As an initial data measure, students who could state 3 steps in the testing would be assigned a $\mathrm{C}$ on an assessment scale. Language used by the student was also recorded and analysed. This information was used in conjunction with the 
number of steps to help ascertain an assessment level for this study.

Prep students were tested at the end of Semester One to determine a baseline level of competencies for sequential thinking, which ultimately I believe is a prerequisite for coding and programming. Using this premise I adopted one of the Australian Curriculum standards for students as an underlying guide for the research,

Follow, describe and represent a sequence of steps and decisions (algorithms) needed to solve simple problems. [2]

Students were then tested in the middle of Term Four using the same questions to gauge their progress in sequential thinking. Data was then put into an excel spreadsheet to analyse results.

Three questions were asked of prep students:

1. What did you do to get ready for school this morning?

2. How did you get to school and which way did you come?

3. If (teacher's name) gave you a letter to take to the office which way would you go?

The first question was used to establish routine and sequential thinking based on their knowledge and understanding taking into consideration their age and development. The next two questions measured the student's ability to observe surroundings and directions following a set path and to recall detail. Note was taken of the language used by the student and was given a scale. This was recorded using AudioNote on an iPad and analysed according to the criteria below.

a) No articulation - for students who were not able to use language to identify steps used

b) Simple - one word answers, e.g. up, down, over there

c) Complex - directional words, e.g. walk straight, turn left, turn right/complete sentences

d) Sophisticated - directional words in relation to locations, e.g. walk past the cream hall, turn right

\section{Data Analysis}

The data indicated improvements were made between pre and post training in both the number of steps children were able to identify and the language used.

a) In question one there was a 3\% improvement in students able to identify 3 or more steps.

b) In question two there was a $29.4 \%$ improvement in students able to identify 3 or more steps.

c) In question three there was a $40.4 \%$ improvement in students able to identify 3 or more steps.

Throughout the unit there was explicit teaching on moving around the school and how to get from one destination to another. This was done by taking the class to another location before morning tea and walking them back up to the computer lab afterwards. On each of these events students used hand signals and had discussions on the route to take to get the new destination. Due to the explicit teaching of navigating the school, it is anticipated this could explain in part the higher improvement in question 3.

Language used by the prep students showed significant improvement over the project. Initially over $70 \%$ of students used simple language, which included one-word answers or directional language (up, down or over there) across all questions.

a) In questions one and two $25.7 \%$ of students used complex directional words (walk straight, turn left or right)

b) In question three $7.1 \%$ were able to do this.

c) In question three $8.6 \%$ were not able to articulate any responses for moving about the school.

After the teaching of the unit there was a significant decrease in students using simple language and improvements were seen in children using complex and sophisticated language.

a) In question one and two there was an improvement in the use of complex language by $33 \%$ and $63 \%$ in question three.

b) In question two and three students exhibited the use of sophisticated language (use of directional language with specified locations).

c) $7.4 \%$ of students used sophisticated language in question two and $16.2 \%$ in question three. Once again, the larger improvement in question three could be influenced by the explicit teaching of moving around the school.

Overall there was improvement in both language and number of sequential steps identified by students from the beginning of the unit to the end of the unit. The premise of this project was to discover the impact of using unplugged activities on the ability of children to identify the number of steps and the language that they used. [16-37] Two classes were used as the control group and the remaining two classes were given a folder that contained examples of unplugged activities that teachers could use in their classrooms. [16-37] Class one used the unplugged activities once a fortnight whilst Class two did the unplugged activities on average twice a week. [16-37]

Data in Tables $1-3$ shows the performance of both Control Classes and Classes using supplementary unplugged activities in both pre and post teaching data.

Table 1. Sequential Steps Comparison between Classes using unplugged activities and Control Classes.

\begin{tabular}{|c|c|c|c|c|c|}
\hline \multicolumn{3}{|l|}{ Pre Data } & \multicolumn{3}{|l|}{ Post Data } \\
\hline \multicolumn{3}{|c|}{ Achieving a C (3 or more sequential steps) } & \multicolumn{3}{|c|}{ Achieving a C ( 3 or more sequential steps) } \\
\hline & Control Classes & Unplugged classes & & Control Classes & Unplugged Classes \\
\hline Question 1 & $91 \%$ & $80.6 \%$ & Question 1 & $93.9 \%$ & $91.4 \%$ \\
\hline Question 2 & $2.6 \%$ & $1.7 \%$ & Question 2 & $54.5 \%$ & $40 \%$ \\
\hline Question 3 & $1.7 \%$ & $30.5 \%$ & Question 3 & $72.7 \%$ & $57.1 \%$ \\
\hline
\end{tabular}


Both the control and unplugged classes showed significant improvements in the identification of steps and language used. The unplugged classes came from a lower base in questions one and two while the control classes' pre data was lower in question three. Gains made in post data were of a magnitude that should have nullified individual student circumstances - e.g. having familiarity with the school surroundings via an older sibling.

Explicit teaching appears to be the catalyst.

Table 2. Language Used (pre) Comparison between Classes using unplugged activities and Control Classes.

\begin{tabular}{|c|c|c|c|c|c|c|c|c|}
\hline \multicolumn{5}{|l|}{ Pre Data } & \multicolumn{4}{|l|}{ Pre Data } \\
\hline \multicolumn{5}{|c|}{ Language Used } & \multicolumn{4}{|l|}{ Language Used } \\
\hline \multicolumn{5}{|c|}{ Control Classes } & \multicolumn{4}{|l|}{ Unplugged Classes } \\
\hline & No Articulation & Simple & Complex & Sophisticated & No Articulation & Simple & Complex & Sophisticated \\
\hline Question 1 & $0 \%$ & $70.6 \%$ & $29.4 \%$ & $0 \%$ & $0 \%$ & $77.8 \%$ & $22.2 \%$ & $0 \%$ \\
\hline Question 2 & $0 \%$ & $76.5 \%$ & $23.5 \%$ & $0 \%$ & $0 \%$ & $72.2 \%$ & $27.8 \%$ & $0 \%$ \\
\hline Question 3 & $11.8 \%$ & $82.4 \%$ & $5.8 \%$ & $0 \%$ & $5.5 \%$ & $86.1 \%$ & $8.4 \%$ & $0 \%$ \\
\hline
\end{tabular}

Table 3. Language Used (post) Comparison between Classes using unplugged activities and Control Classes.

\begin{tabular}{|c|c|c|c|c|c|c|c|c|}
\hline \multicolumn{5}{|l|}{ Post Data } & \multicolumn{4}{|l|}{ Post Data } \\
\hline \multicolumn{5}{|c|}{ Language Used } & \multicolumn{4}{|l|}{ Language Used } \\
\hline \multicolumn{5}{|c|}{ Control Classes } & \multicolumn{4}{|l|}{ Unplugged Classes } \\
\hline & No Articulation & Simple & Complex & Sophisticated & No Articulation & Simple & Complex & Sophisticated \\
\hline Question 1 & $0 \%$ & $54.5 \%$ & $45.5 \%$ & $0 \%$ & $0 \%$ & $28.6 \%$ & $71.4 \%$ & $\mathrm{O} \%$ \\
\hline Question 2 & $0 \%$ & $48.5 \%$ & $42.4 \%$ & $9.1 \%$ & $0 \%$ & $20 \%$ & $74.3 \%$ & $5.7 \%$ \\
\hline Question 3 & $0 \%$ & $12.1 \%$ & $69.7 \%$ & $18.2 \%$ & $0 \%$ & $14.3 \%$ & $71.4 \%$ & $14.3 \%$ \\
\hline
\end{tabular}

Table 2 and 3 demonstrate a clear shift from simple to more complex and sophisticated language. Unplugged classes show a stronger use of complex language than the Control Classes over all three questions. Control Classes showed a higher use of sophisticated language and this could possibly be attributed to teachers in the unplugged classes not having a consistent language and knowledge base of the metalanguage of Digital Technologies concepts.

Data in Tables 4 - 6 shows the performance of both streams of the Classes using supplementary unplugged activities using and both pre and post teaching data.

Table 4. Sequential Steps Comparison between classes using unplugged activities.

\begin{tabular}{|c|c|c|c|c|c|}
\hline \multicolumn{3}{|l|}{ Pre Data } & \multicolumn{3}{|l|}{ Post Data } \\
\hline \multicolumn{3}{|c|}{ Achieving a C ( 3 or more sequential steps) } & \multicolumn{3}{|c|}{ Achieving a C (3 or more sequential steps) } \\
\hline & Class 2 & Class 1 & & Class 2 & Class 1 \\
\hline Question 1 & $94.4 \%$ & $72.2 \%$ & Question 1 & $94.1 \%$ & $88.9 \%$ \\
\hline Question 2 & $33.3 \%$ & $0 \%$ & Question 2 & $58.8 \%$ & $22.2 \%$ \\
\hline Question 3 & $16.6 \%$ & $44.4 \%$ & Question 3 & $70.9 \%$ & $44.4 \%$ \\
\hline
\end{tabular}

Data from Table 4 analysed the difference between the two classes that used the unplugged activities. Class 2, which did the unplugged activities on average twice a week, showed significant improvement over Class 1, which did the unplugged activities once a fortnight. The improvement was over both number of steps identified and in the complexity of language used.

Table 5. Language Used (pre) Comparison between Classes using unplugged activities.

\begin{tabular}{|c|c|c|c|c|c|c|c|c|}
\hline \multicolumn{5}{|l|}{ Pre Data } & \multicolumn{4}{|l|}{ Pre Data } \\
\hline \multicolumn{5}{|c|}{ Language Used } & \multicolumn{4}{|l|}{ Language Used } \\
\hline \multicolumn{5}{|l|}{ Class 2} & \multicolumn{4}{|l|}{ Class 1} \\
\hline & No Articulation & Simple & Complex & Sophisticated & No Articulation & Simple & Complex & Sophisticated \\
\hline Question 1 & $0 \%$ & $55.6 \%$ & $44.4 \%$ & $0 \%$ & $0 \%$ & $100 \%$ & $0 \%$ & $0 \%$ \\
\hline Question 2 & $0 \%$ & $66.7 \%$ & $33.3 \%$ & $0 \%$ & $0 \%$ & $77.8 \%$ & $22.2 \%$ & $0 \%$ \\
\hline Question 3 & $11.1 \%$ & $83.3 \%$ & $5.6 \%$ & $0 \%$ & $0 \%$ & $88.9 \%$ & $11.1 \%$ & $0 \%$ \\
\hline
\end{tabular}

Table 6. Language Used (post) Comparison between Classes using unplugged activities.

\begin{tabular}{|c|c|c|c|c|c|c|c|c|}
\hline \multicolumn{5}{|l|}{ Post Data } & \multicolumn{4}{|l|}{ Post Data } \\
\hline \multicolumn{5}{|c|}{ Language Used } & \multicolumn{4}{|l|}{ Language Used } \\
\hline \multicolumn{5}{|l|}{ Class 2} & \multicolumn{4}{|l|}{ Class 1} \\
\hline & No Articulation & Simple & Complex & Sophisticated & No Articulation & Simple & Complex & Sophisticated \\
\hline Question 1 & $0 \%$ & $5.9 \%$ & $94.1 \%$ & $0 \%$ & $0 \%$ & $50 \%$ & $50 \%$ & $0 \%$ \\
\hline Question 2 & $0 \%$ & $11.7 \%$ & $76.5 \%$ & $11.8 \%$ & $0 \%$ & $27.8 \%$ & $72.2 \%$ & $0 \%$ \\
\hline Question 3 & $0 \%$ & $5.9 \%$ & $70.6 \%$ & $23.5 \%$ & $0 \%$ & $22.2 \%$ & $72.2 \%$ & $5.6 \%$ \\
\hline
\end{tabular}


Differences in the classes that undertook the unplugged activities should be noted. The teacher of Class 2 has used ICT technologies throughout her career and has shown great interest in the new curriculum area of Digital Technologies. The teacher of Class 1 is a relative novice with Digital Technologies and has undertaken some professional development this year to enhance her knowledge in this area. The difference in level of expertise in using Digital Technologies by the teacher and the frequency of the events could have impacted on class results.

Comparisons were then taken between the Control classes and class 1 and class 2 . There was a difference of approximately $15 \%$ between the control class and unplugged classes in achieving a $\mathrm{C}$ standard (identifying 3 or more steps) over questions 2 and 3 and no substantive difference in question 1, with the control classes achieving the higher score. There was minimal difference between the control classes and class 2 (class with the teacher with more experience with Digital Technologies) in achieving a C standard. With Class 1 achieving a lower percentage than the control classes.

Table 7. Sequential Steps Comparison between Control classes, Class 1 and Class 2.

\begin{tabular}{|c|c|c|c|}
\hline \multicolumn{4}{|l|}{ Pre Data } \\
\hline \multicolumn{4}{|c|}{ Achieving a C (3 or more steps) } \\
\hline & Control Classes & Class 1 & Class 2 \\
\hline Question 1 & $91 \%$ & $72.2 \%$ & $94.4 \%$ \\
\hline Question 2 & $2.6 \%$ & $0 \%$ & $33.3 \%$ \\
\hline Question 3 & $1.7 \%$ & $44.4 \%$ & $16.6 \%$ \\
\hline \multicolumn{4}{|l|}{ Post Data } \\
\hline \multicolumn{4}{|c|}{ Achieving a C (3 or more steps) } \\
\hline & Control Classes & Class 1 & Class 2 \\
\hline Question 1 & $93.9 \%$ & $88.9 \%$ & $94.1 \%$ \\
\hline Question 2 & $54.5 \%$ & $22.2 \%$ & $58.8 \%$ \\
\hline Question 3 & $72.7 \%$ & $44.4 \%$ & $70.9 \%$ \\
\hline
\end{tabular}

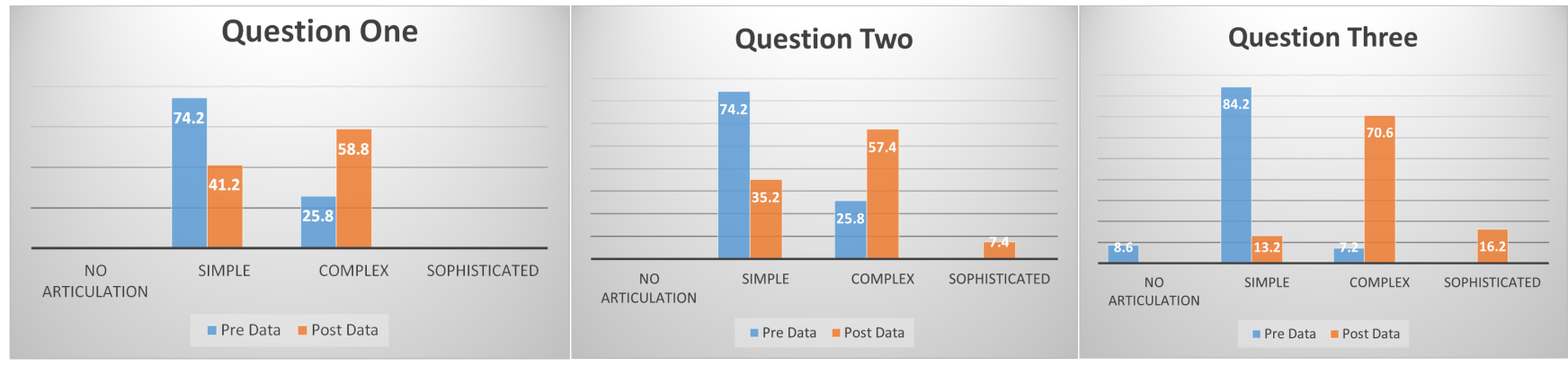

Figure 1. Language Used.

In question 1 the language usage recorded by Class 2 showed an improvement in the use of complex language by $44.1 \%$ over Class 1 and $48.6 \%$ over the control class. The data collected in question 2 indicated the unplugged class showed an improvement in the usage of complex language over the control class by an average of $32 \%$. Class 2 had an increase in the use of sophisticated language over the control classes by $2.7 \%$. Question 3 showed that there was minimal difference in the use of complex language however there was a difference of $5.3 \%$ in the use of sophisticated language between Class 2 and the control class.

In summary there were gains achieved from the pre data to the post data across all classes in both sequential steps identified and language used. Whilst there were differences in the data between the control classes and unplugged classes it varied from question to question and the data was also skewed between the two unplugged classes due to the different teaching emphasis. The significant difference in data occurred between the pre and post data with a higher percentage of students achieving a $\mathrm{C}$ standard at the end of the unit and the shift in language used from simple through to more complex language and continuing through to the use of sophisticated language.

\section{Implications}

The purpose of this project was to determine if the use of unplugged activities as an additional activity by the classroom teacher significantly enhanced the capacity of students to grasp the programming skills taught by the specialist teacher. [16-37] This information was then used to structure Professional Development for teachers next year in the curriculum area of Digital Technologies. The difference in the data between the two unplugged classes highlighted the different skill set that the teachers developed in Digital Technologies. This has an impact on how the professional development should be implemented. The original premise was that the Year one teachers would be given a more intensive program to include unplugged activities in their classroom.

The implications from this study would suggest that it would be more beneficial to develop a deeper knowledge of the Digital Technologies curriculum and to implement a consistent language that would be used by everyone across the school. Queens University of Charlotte reinforces the upskilling of teacher knowledge not only to ensure the best learning outcomes for their students but also to be more 
effective and satisfied in various other aspects of their work. [13] Once the knowledge and language base has been implemented and imbedded into the curriculum area across the school, the implementation of unplugged activities across the school would have more benefit. [16-37]

\section{References}

[1] Alam, S. (2011). Information Technology and Education. Pakistan \& Gulf Economist, 30 (16), p. 106.

[2] Australiancurriculum.edu.au. (2020). Technologies. [online] Available at: https://www.australiancurriculum.edu.au/f-10curriculum/technologies/ [Accessed 05 Dec. 2019].

[3] Barefootcas.org.uk. (2020). Concepts and Approaches Category Master Page. [online] Available at: $\mathrm{http}$ ://barefootcas.org.uk/barefoot-primary-computingresources/concepts/computational-thinking/ [Accessed 15 Oct. 2019].

[4] Bell T. Vahrenhold J. (2018). CS Unplugged-How Is It Used, and Does It Work?. In: Böckenhauer HJ., Komm D., Unger W. (eds) Adventures Between Lower Bounds and Higher Altitudes. Lecture Notes in Computer Science, 11011. Springer, Cham.

[5] Chawla, D. (2018). The need for digital intelligence. Nature, 562 (77725), pp. S15-S16.

[6] Education Queensland. (2016). Digital Technologies PowerPoint - Digital Technologies Launch School, [Accessed 25 May 2016].

[7] Staff.learningplace.eq.edu.au. (2020). Submit Form. [online] Available https://staff.learningplace.eq.edu.au/Pages/default.aspx [Accessed 11 Nov. 2020].

[8] Foundation for Young Australians. (2015). The new work order: ensuring young Australians have skills and experience for the jobs of the future, not the past, Foundation for Young Australians, Available at: http://apo.org.au/node/56888 [10 Nov. 2016],

[9] Epstien, A. (2013). Helping Preschoolers Build Their Thinking Skills. Teaching Young Children, 7 (1), pp. 20 - 23.

[10] Logofatu, B. (2013). The International Scientific Conference eLearning and Software for Education; Bucharest. 1, pp. 610615. Burcharest:"Carol 1" National Defence University.

[11] McQuiggan, S., McQuiggan, J., Sabourin, J. and Kos. (2015). Mobile Learning: A Handbook for Developers, Educators, and Learners. John Wiley \& Sons.

[12] Momoh, E. (2018). Information Technology and the Future of Librarianship. Library Philosophy and Practice, pp. 1-6.

[13] Programs, O., Leadership, M., Resources, E., Educators, T. and Charlotte, Q. (2020). The Importance of Professional Development for Educators. [online] Queens University of Charlotte Online. Available https://online.queens.edu/onlineprograms/medl/resources/professional-development-foreducators [Accessed 28 Nov. 2019].

[14] Uk.sagepub.com. (2020). [online] Available at: https://uk.sagepub.com/sites/default/files/upmbinaries/77010_00a_Caldwell_Intro.pdf [Accessed 01 Jan. 2020].

[15] Whittaker, J. (2014). Good Thinking!: Fostering Children's Reasoning and Problem Solving. Young Children, 69 (3), pp. 80-89.

[16] Atkinson, R., Dalgleish, S. and Mercer, J. (1990) Down Amongst the Gum Trees: Australian stories to tell and make. Brookvale: Educational Supplies Pty Ltd.

[17] Beals, G. (1993) Listening Comprehension - Lower, Warwickshire: Prim-Ed Publishing.

[18] Bishop, R. (1988) Inside Stories: Exploring story structure with young children. Gosford: Ashton Scholastic.

[19] Brand, T. and Bacich, N. (1998) Nursery Rhymes -Year 1: Sequential across-the-curriculum activities. Warwickshire: Prim-Ed Publishing.

[20] Brand, T. and Bacich, N. (1998) Bears -Year 1: Sequential across-the-curriculum activities. Warwickshire: Prim-Ed Publishing.

[21] Brand, T. and Bacich, N. (1998) The Sea-Year 1: Sequential across-the-curriculum activities. Warwickshire: Prim-Ed Publishing.

[22] Chambers, J. and Watson, S. (2000) Art in the Sun. Brookvale: Educational Supplies Pty Ltd.

[23] Cherrie, D. and McCulloch, M. (1996) New Ways with Nursery Rhymes. Greenwood: R. I. C. Publications.

[24] Connolly, C. (1996) 30 Maths Games for Lower Primary. Warwickshire: Prim-Ed Publishing.

[25] Coppock, L. (1999) Outstanding Art: Imaginative threedimensional art and sculpture. Dunstable: Belair Publications Ltd.

[26] Dacey, L., Gartland, K. and Bamford Lynch, J. (2016) Well Played: Building Mathematical Thinking Trough Number Games and Puzzles - Grades K-2. Moorabbin: Hawker Brownlow Education.

[27] Evans, J. (2007) Science: Early Years activities to promote scientific understanding. Brookvale: Educational Supplies Pty Ltd.

[28] Evans, J. and Skelton, T. (2001) How to Teach Art to Children. Monterey: Evan-Moor Educational Publishers.

[29] Geller, K. (2005) Follow-the-Directions: Draw \& Write Activities: Step-by-Step Directions and Writing Prompts that guide children to draw pictures and write stories about them. New York: Scholastic Inc.

[30] Gerdemann, G. \& Barta, K. (2014) Maths Games for the Australian Curriculum: Understanding key mathematic concepts and strengthening skills. Greenwood: R. I. C Publications.

[31] Dilpin, R. and Pratt, L. (2007) The Usborne Big Book of Science things to make and do. London: Usborne Publishing Ltd.

[32] Moore, J. E. and Tryon, L. (1986) Life Cycles: Science Sequencing. Monterey: Evan-Moor Corp. 
[33] Schecter, D. (2008) Teaching Reading \& Writing with Nursery Rhymes: Activities, Games, and manipulatives that teach sight words and phonics skills, build vocabulary, boost comprehension, and more. New York: Scholastic Inc.

[34] Schecter, D. (2008) Nursery Rhymes: Adorable art projects with easy directions and rebus support that build beginning reading skills. New York: Scholastic Inc.
[35] 501 Science Experiments. (2007) Heatherton: Hinkler Books Pty Ltd.

[36] Stoikovich, V. and Tebbutt, L. (1995) Junior Visual Arts for Teachers. Toongabbie: Holding Educational Aids.

[37] Usborne Art ideas. (2002) London: Usborne Publishing Ltd. 